\title{
Research about Component Enzyme Making Antibacterial Paper
}

\author{
Du Fei1 a, Li Zhi-jian1b, Wang Ji-qing1c, Mao Yu1d \\ School of Light Industry and Energy, Shannxi University of Science \& Technology, Xi'an China \\ aemail:dufeilily@126.com, bemail:lizj@sust.edu.cn, cemail:anlongzhang63@163.com
}

Key words: component enzyme, antibacterial paper, antibacterial annulus

\begin{abstract}
The article researched a kind of green antibacterial paper based component enzyme. The glucose oxidase and lysozymein were added in paper by coating. And the article researched the antimicrobial effect through antibacterial annulus and SEM. The optimum antimicrobial effect that used glucose oxidase only was $\mathrm{pH}=5.5$ and enzyme activity 4000-6000u/g (on even dry pulp). And then the optimum antimicrobial effect that used ysozymein only was $\mathrm{pH}=5.5$ and enzyme activity 4000-6000u/g (on even dry pulp). Antibacterial annulus and TEM showed the antimicrobial effect that used component enzyme in paper surface was better. Furthermore, enzyme activity dosage of component enzyme was lower than single use. The optimum condition was enzyme activity of glucose oxidase $4000 \mathrm{u} / \mathrm{g}$ (on even dry pulp), enzyme activity of lysozymein $20000 \mathrm{u} / \mathrm{g}$ (on even dry pulp) and $\mathrm{pH}=6.0$.
\end{abstract}

\section{Introduction}

Antibacterial paper research is a new field of antibacterial material in recent years. There are many ways give paper and paper products antibacterial function .Common method in the paper is join inorganic or organic antibacterial agents, it can give paper or paper products certain antibacterial properties to some extent. However, The traditional type of organic inorganic antibacterial agents has been unable to meet the requirements of people for green and harmless, Such as paper of newborn babies, female paper, medical paper, etc [1-8].This article selection of glucose oxidase and lysozymein, is a kind of biological antibacterial agents which have catalytic ability of singleness. It is completely harmless to the human body and easy degradation in nature and does not produce any pollution to the environment. So using glucose oxidase and lysozyme as production of antibacterial paper, is really in the sense of pure green antibacterial paper. Two enzymes were added in paper by coating in this article. Study antibacterial effect when they are used alone and complex formulation. Then obtain the optimum process parameters of producing antibacterial paper by component enzyme.

\section{Materials}

(1)The raw material: Hardwood pulp board

(2)Chemicals: glucose oxidase: enzyme activity 50000U.g-1, lysozymein: enzyme activity 30000U. mg-1,Glucose solid (analytically pure ),Acetic acid, sodium acetate (analytically pure)

(3)reagent: glucose solution( concentration $0.5 \mathrm{~mol} / \mathrm{L}$ );0.9\% sodium chloride solution; $\mathrm{pH}=5.5$ 
Acetic acid, sodium acetate buffer; $\mathrm{pH}=6.5$ Acetic acid, sodium acetate buffer

(4)Bacterial species: E. coli

\section{Equipment}

(1)Paper making equipment

(2)Bacteria inoculation and incubation equipment

Flat dish, vaccination needle, High pressure sterilization pot, inoculation loops, constant temperature and humidity box, biological incubator

\section{The results and Analysis}

The antimicrobial effect research of antibacterial paper made by lysozymein

The experimental method[9-10]. (1)According to previous research of antimicrobial effect. The amount of lysozyme in 1000-5000 u/ml had good antibacterial effect. So the preparation of 1000 , 2000, 3000, 4000, $5000 \mathrm{u} / \mathrm{ml}$ of lysozyme solution.

(2)According to per gram dry pulp enzyme dosage and concentration of the enzyme solution. A certain amount of enzyme solution evenly uniformed on manufacture paper with a glass rod, drying in $37{ }^{\circ} \mathrm{C}$ Air-blower-driven Drying Closet, Take out and use sterilized scissors to cut a diameter of $20 \mathrm{~mm}$ of paper and well marked.

(3) Vaccinated E. coli by spread plate method,pieces of paper put on a flat dish by using tweezers.

(4)Put a dish at $30{ }^{\circ} \mathrm{C}$ biochemical incubator for $48 \mathrm{~h}$.

The Antimicrobial Effect of Antibacterial Paper Made by Lysozymein. After 48h cultivate for E. Coli, the antimicrobial effect of antibacterial paper made by lysozymein (antibacterial annulus) shown in table 1, the diameter of antibacterial annulus has shown in table1, figure 2.
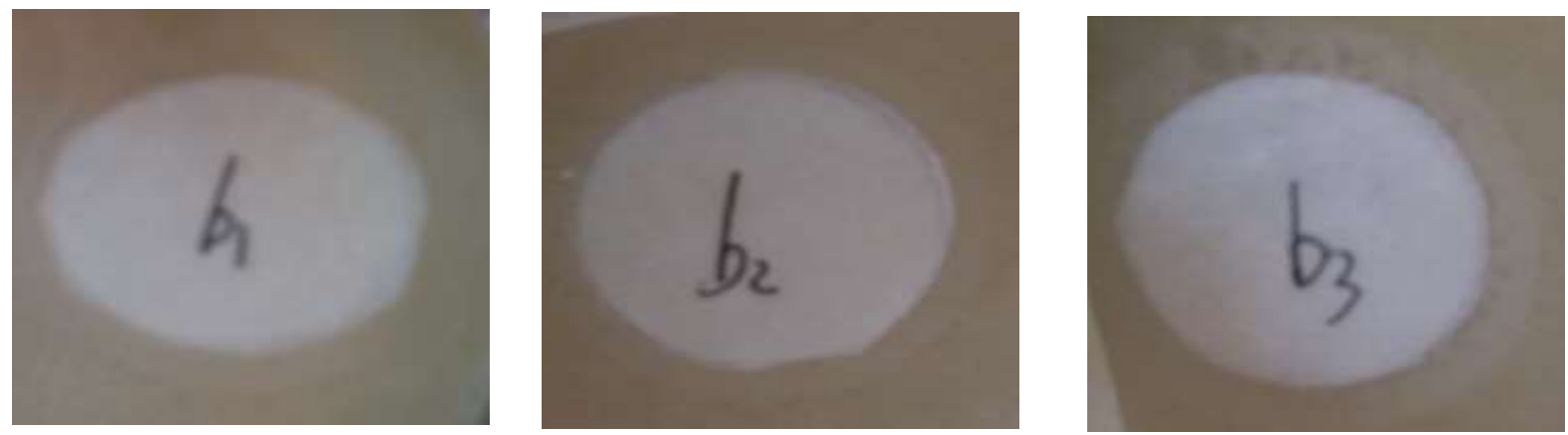

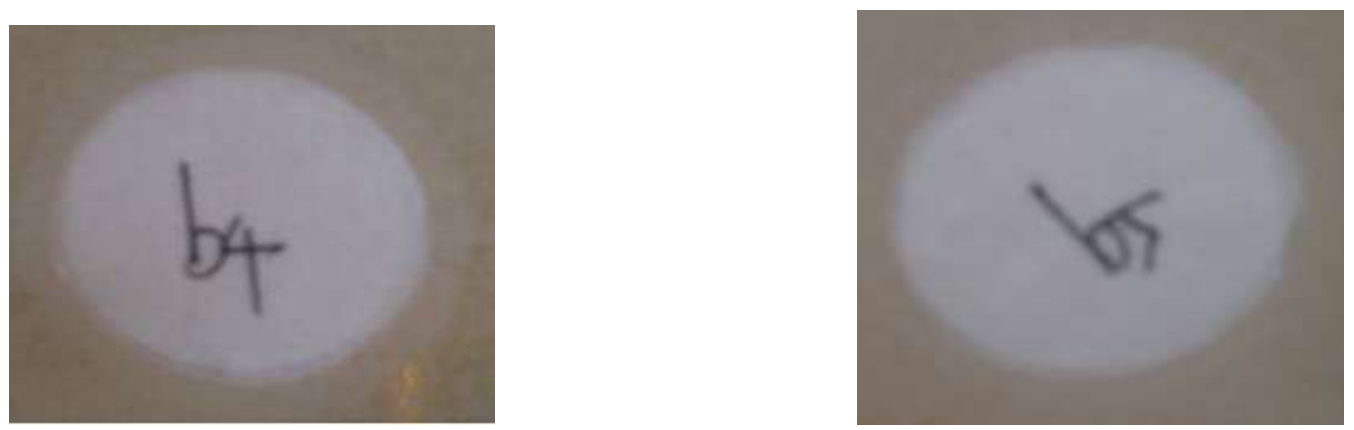

Fig. 1: antibacterial annulus photograph of antibacterial paper made by lysozymein

Table1 antibacterial annulus diameter of antibacterial paper made by lysozymein

\begin{tabular}{lccccc}
\hline Sample name & b1 & b2 & b3 & b4 & b5 \\
\hline $\begin{array}{l}\text { Lysozymein } \\
\text { dosage(on even } \\
\text { dry oulp) }\end{array}$ & 5000 & 10000 & 15000 & 20000 & 25000 \\
\hline dimaeter(mm) & 23.1 & 24.2 & 24.4 & 25.2 & 25.2 \\
\hline
\end{tabular}

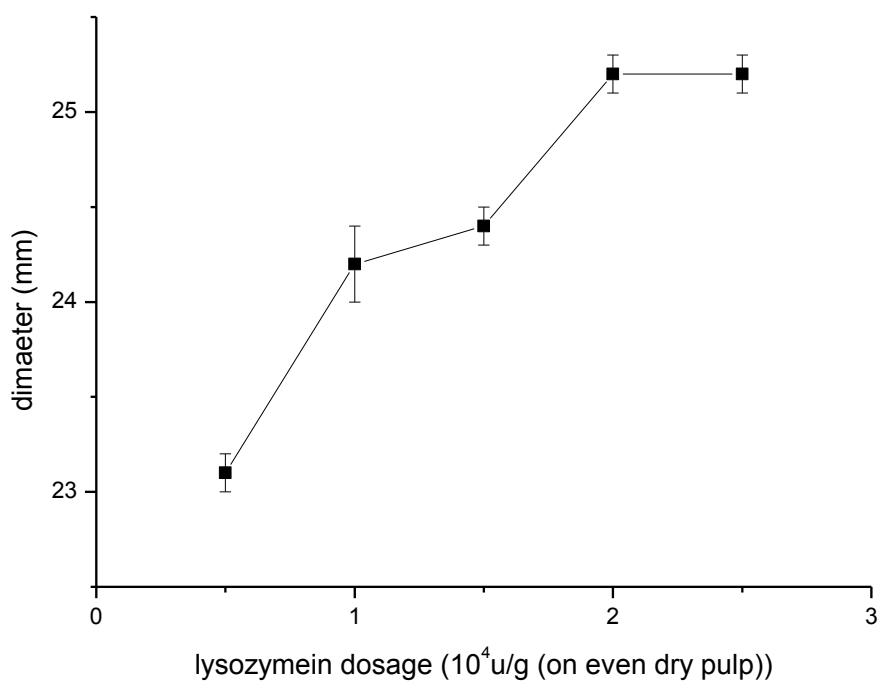

Fig. 2: The change of antibacterial annulus diameter with lysozymein dosage of antibacterial paper made by lysozymein

As shown in figure 2-1, on the edge of the b1 - b5 paper have formed the antibacterial annulus of light color, the growth of antibacterial annulusand e. colion paper was obvious inhibited. It has shown some antimicrobial effect of antibacterial paper made by lysozymein.Table1, figure2shown antibacterial annulus diameters of paper made by different lysozymein dosage. From table1, figure 2 can be seen, lysozyme dosage in 5000-20000 (u/g on even dry pulp) range. The antimicrobial effect of paper have more obvious improve when increase the lysozymein dosage. When lysozymein dosage has exceed 20000 (u/g on even dry pulp). The antimicrobial effect of paper have no obvious change when increase the lysozymein dosage. Considering the antimicrobial effect of antibacterial paper and the cost of antibacterial, the lysozymein dosage is better not over 25000 (u/g on even dry pulp). 


\section{The Antimicrobial Effect Research of Antibacterial Paper Made by Glucose Oxidase}

The Experimental Method. (1)According to previous research of antimicrobial effect. The amount of glucose oxidase in 400-1200 u/ml had good antibacterial effect. So the preparation of 400, 600, $3000,800,1000,1200 \mathrm{u} / \mathrm{ml}$ of glucose oxidase solution.

(2)According to per gram dry pulp enzyme dosage and concentration of the enzyme solution. A certain amount of enzyme solution evenly uniformed on manufacture paper with a glass rod, drying in $37^{\circ} \mathrm{C}$ Air-blower-driven Drying Closet, take out and use sterilized scissors to cut a diameter of $20 \mathrm{~mm}$ of paper and well marked.

(3)Vaccinated E. coli by spread plate method, pieces of paper put on a flat dish by using tweezers.

(4)Put a dish at $30^{\circ} \mathrm{C}$ biochemical incubator for $48 \mathrm{~h}$.

The Antimicrobial Effect of Antibacterial Paper Made by Lysozymein. After $48 \mathrm{~h}$ cultivate for E. Coli, the antimicrobial effect of antibacterial paper made by glucose oxidase (antibacterial annulus) shown in figure 2-3, the diameter of antibacterial annulus shown in table 2-2, figure 2-4.
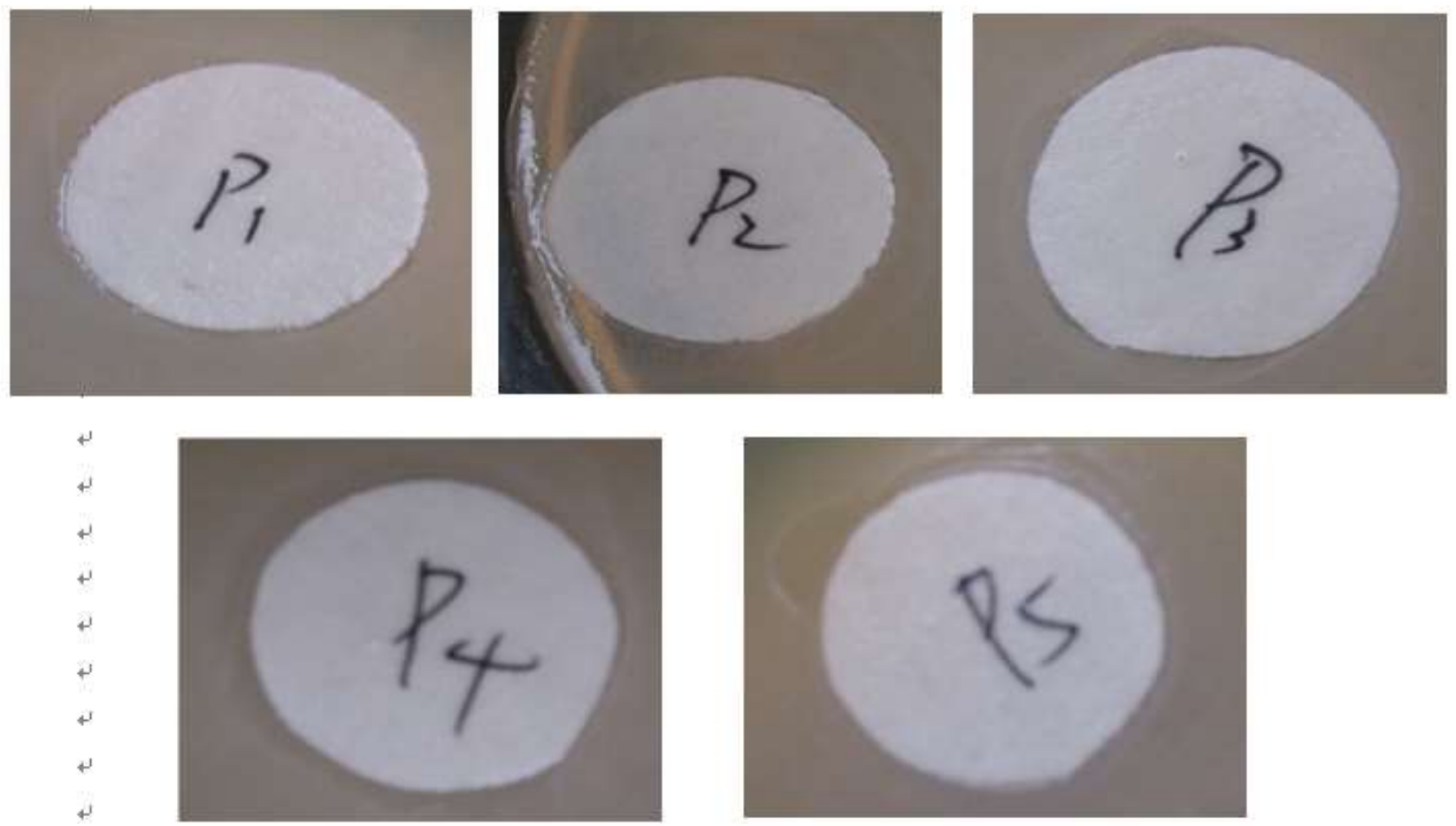

Figure 3 antibacterial annulus photograph of antibacterial paper made by glucose oxidase

As shown in figure 3, on the edge of the p1 - p5 paper have formed the antibacterial annulus of light color. But compared to figure 1 it seems no matter significance level or size of antibacterial annulus are not better than lysozymein. The antimicrobial effect that separate use of glucose oxidase as antimicrobial agent to make paper is no better than lysozymein. Analysis the reason, may due to the main antibacterial principle of glucose oxidase is decomposition of oxygen around the paper. This is a kind of indirect antimicrobial by excludes oxygen .And the antimicrobial effect of the 
lysozyme embodied in direct antimicrobial of bacteria as the role of the substrate.Table2, figure 4 shown antibacterial annulus diameters of paper made by different glucose oxidase dosage. From table2, figure 4 can be seen the improve of its antimicrobial effect with the increase of glucose oxidase dosage. But the extend of increase will be down when glucose oxidase dosage over 5000(u/g on even dry pulp).So Considering the antimicrobial effect of antibacterial paper and the cost of antibacterial, the glucose oxidase dosage is better not over 6000 (u/g on even dry pulp).

Table 2. Antibacterial annulus diameter of antibacterial paper made by glucose oxidase

\begin{tabular}{llllll}
\hline Sample name & $\mathrm{p} 1$ & $\mathrm{p} 2$ & $\mathrm{p} 3$ & $\mathrm{p} 4$ & $\mathrm{p} 5$ \\
\hline $\begin{array}{l}\text { oxidase dosage } \\
\text { (on even dry oulp) }\end{array}$ & 2000 & 3000 & 4000 & 5000 & 6000 \\
\hline dimaeter(mm) & 20.8 & 21.5 & 22.3 & 23.0 & 23.2 \\
\hline
\end{tabular}

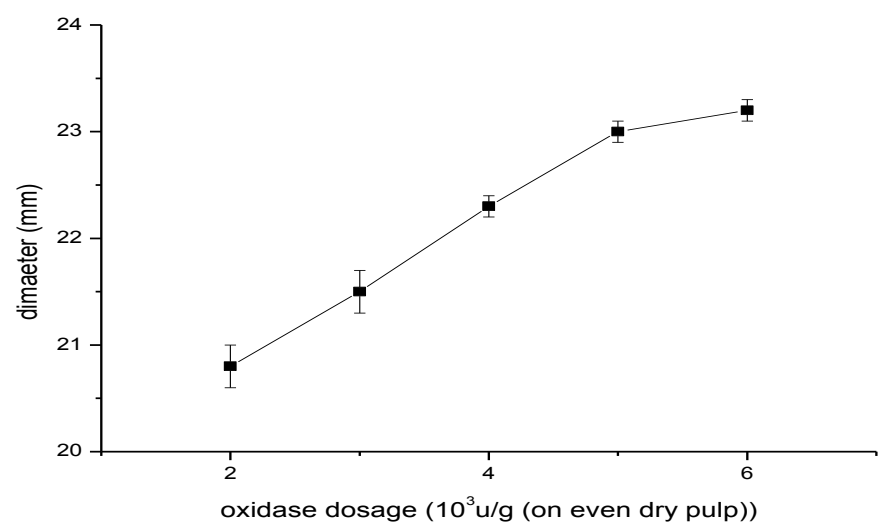

Fig. 4: The change of antibacterial annulus diameter with oxidase dosage of antibacterial paper made by glucose oxidase

The Antimicrobial Effect Research of Antibacterial Paper Made by Component Enzyme. In order to increase the antimicrobial effect of antibacterial paper and reduce the dosage of antimicrobial enzymes. The article makes paper by component glucose oxidase and lysozymein. Play a direct antimicrobial effects of lysozyme and indirect antimicrobial effects of glucose oxidase at the same time.

The Experimental Method. (1)Preparation of 2000, 3000, $4000 \mathrm{u} / \mathrm{ml}$ lysozyme solution with $\mathrm{pH}$ $5.5,6,6.5$ and $1600,2000,2400 \mathrm{u} / \mathrm{ml}$ glucose oxidase solution.

(2)According to figure 2-3, mixed the dosage of 1:1 and evenly uniformed on manufacture paper with a glass rod, drying in $37^{\circ} \mathrm{C}$ Air-blower-driven Drying Closet. Take out and use sterilized scissors to cut a diameter of $20 \mathrm{~mm}$ of paper and well marked.

(3)Vaccinated E. coli by spread plate method, pieces of paper put on a flat dish by using tweezers. (4)Place upside down the dish and put it at $30^{\circ} \mathrm{C}$ biochemical incubator for $48 \mathrm{~h}$.

The Antimicrobial Effect Research of Antibacterial Paper Made by Component Enzyme. After manufacture paper, composite enzyme as an antimicrobial agent, inoculated the e. coli and biochemical incubator for $48 \mathrm{~h}$. The antimicrobial effect shown in figure5, the diameter of 
antibacterial annulus has shown in table 4, figure6.

As shown in figure 5, the Composite enzyme as an antimicrobial agent make the paper and antibacterial annulus effect of antimicrobial paper is obvious. Antibacterial annulus edge can be clearly seen. the e. Coli hardly to see inside the antibacterial annulus or on the paper. Even the density of e. coli around antibacterial annulus is low. It is to say use composite enzyme make paper is better than single enzyme. In combination with figure 2-6, table 2-4, it can be seen that the best antibacterial effect of NO.9 can reach $26.2 \mathrm{~mm}$. The process parameters is $\mathrm{pH}=6.1$ ysozymein dosage is $10000(\mathrm{u} / \mathrm{g}$ on even dry pulp).glucose oxidase dosage is $6000(\mathrm{u} / \mathrm{g}$ on even dry pulp).To reach the best antibacterial effect, the dosage of the two enzymes are lower than when used alone. Thus it can be seen, using glucose oxidase and lysozyme as component enzyme will not produce mutual inhibition, but also promote each other. Play a direct antimicrobial effects of lysozyme and indirect antimicrobial effects of glucose oxidase at the same time. In order to prove both promote action of antibacterial, the experiment take the e. Coli which around the antibacterial annulus to make TEM.As shown in figure 2-7. Figure 2-7 illustrates that E. coli on the edge of antibacterial annulus lost most of the cell wall. Part of the e. coli cells structure is not complete. This degree of cell damage is usually caused by oxygen pressure and the cells erosion of the outsider [11-13]. So on the surface or around the antibacterial paper made by component enzyme, two enzymes both played a antibacterial effect itself and have the effect of the mutual promotion.

Table 2-3. The table of orthogonal experiment.

\begin{tabular}{cccc}
\hline NO. & oxidase dosage(on even dry oulp) & $\begin{array}{c}\text { Lysozymein dosage(on even dry } \\
\text { oulp) }\end{array}$ & pH \\
\hline 1 & 4000 & 5000 & 5.5 \\
2 & 4000 & 7500 & 6 \\
3 & 4000 & 10000 & 6.5 \\
4 & 5000 & 5000 & 6 \\
5 & 5000 & 7500 & 6.5 \\
6 & 5000 & 10000 & 5.5 \\
7 & 6000 & 5000 & 6.5 \\
8 & 6000 & 7500 & 5.5 \\
9 & 6000 & 10000 & 6 \\
\hline
\end{tabular}

Table 4. Antibacterial annulus diameter of antibacterial paper made by component enzyme.

\begin{tabular}{|c|c|c|c|c|c|c|c|c|c|}
\hline $\begin{array}{c}\text { Sample } \\
\text { name }\end{array}$ & 1 & 2 & 3 & 4 & 5 & 6 & 7 & 8 & 9 \\
\hline $\begin{array}{c}\text { dimaeter } \\
(\mathrm{mm})\end{array}$ & 22.2 & 25.0 & 25.5 & 22.5 & 22.8 & 21.5 & 22.6 & 22.0 & 26.2 \\
\hline
\end{tabular}

\section{Summary}

According to the research, no matter antibacterial paper made by glucose oxidase and lysozymein alone or by component enzyme both have a good and real green antibacterial effect. The conclusion is as follows:

Lysozyme dosage in 5000-20000 (u/g on even dry pulp) range, antibacterial effect increased 
significantly, the largest diameter of antibacterial annulus is $25.2 \mathrm{~mm}$, When lysozymein dosage has exceed 20000 (u/g on even dry pulp), The antimicrobial effect of paper have no obvious change when increase the lysozymein dosage. Considering the antimicrobial effect of antibacterial paper and the cost of antibacterial, the lysozymein dosage is better not over 25000 (u/g on even dry pulp).

The antimicrobial effect that separate use of glucose oxidase as antimicrobial agent to make paper is not better than lysozymein. The largest diameter of antibacterial annulus is $23.2 \mathrm{~mm}$. The improve of its antimicrobial effect with the increase of glucose oxidase dosage. But the extend of increase will be down when glucose oxidase dosage over 5000(u/g on even dry pulp).Considering the antimicrobial effect of antibacterial paper and the cost of antibacterial, the glucose oxidase dosage is better not over 6000 (u/g on even dry pulp).

The Composite enzyme as an antimicrobial agent make the paper and antibacterial annulus effect of antimicrobial paper is well. $\mathrm{pH}=6$,Lysozyme dosage is $10000 \mathrm{u} / \mathrm{g}$ on even dry pulp),glucose oxidase dosage is 6000 (u/g on even dry pulp), the largest diameter of antibacterial annulus is $26.2 \mathrm{~mm}$. To reach the best antibacterial effect, the dosage of the two enzymes are lower than when used alone.

TEM show that the E. Coli cells damage is usually caused by oxygen pressure and the cells erosion of the outsider. On the surface or around the antibacterial paper made by component enzyme. The lysozyme that bacteria as the substrate happened the directly antibacterial effect and the glucose oxidase that oxygen as the substrate happened the indirectly antibacterial effect .Both of them have the effect of the mutual promotion.
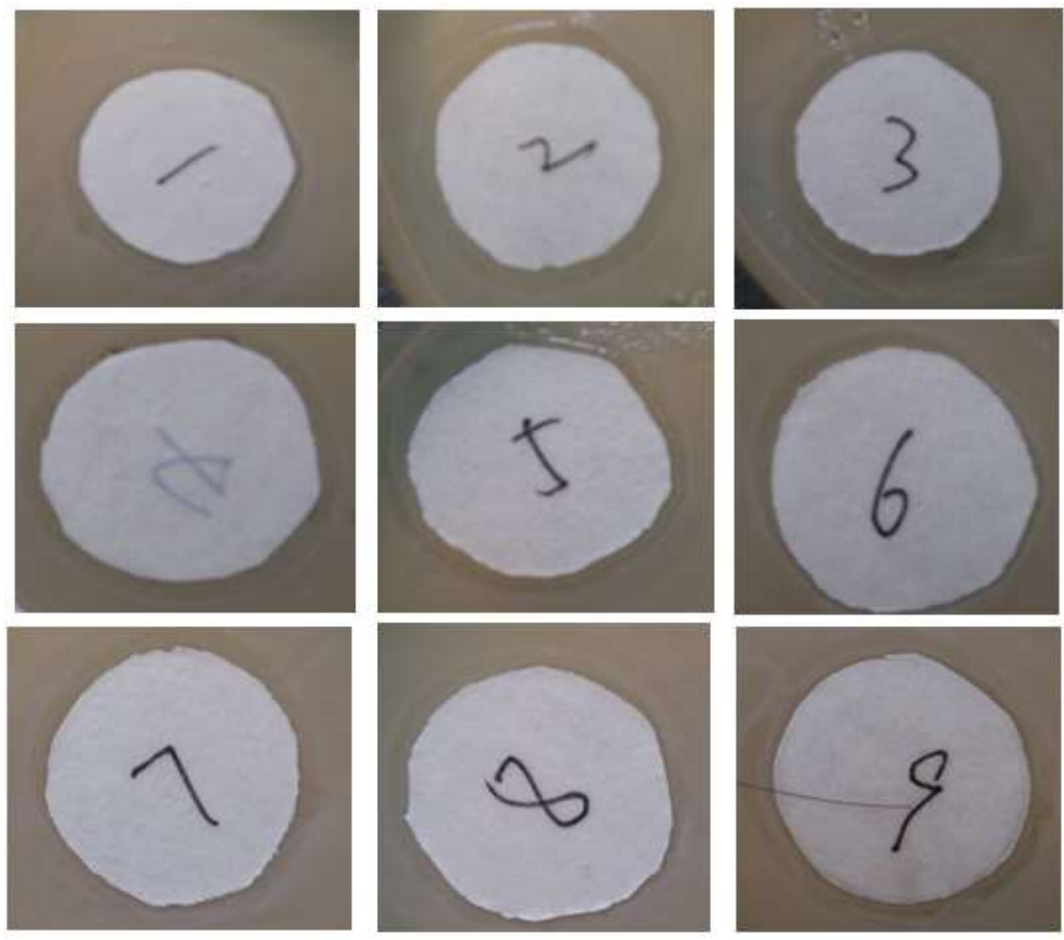

Fig. 2-5. Antibacterial annulus photograph of antibacterial paper made by component enzyme 


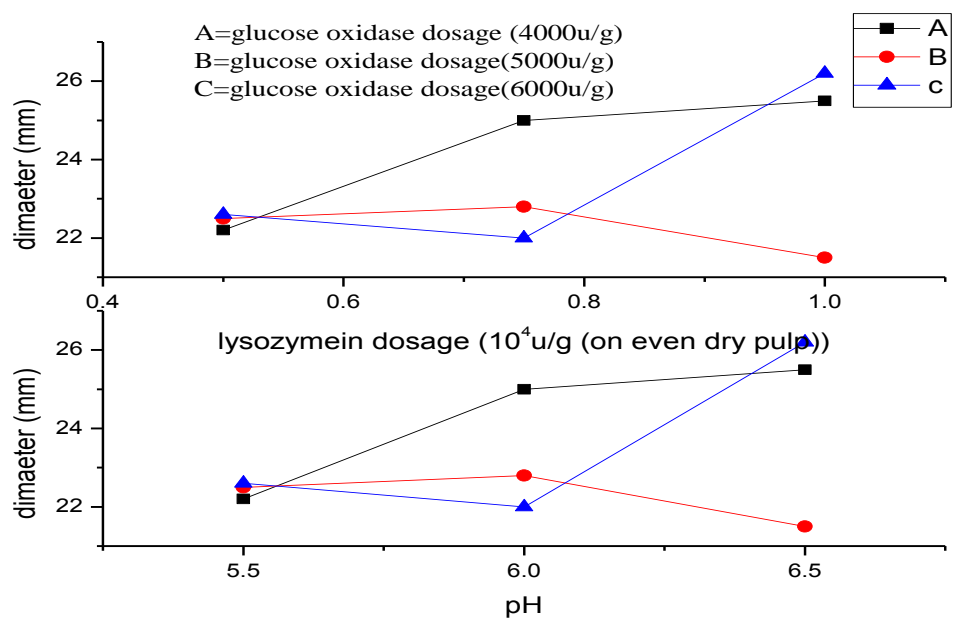

Fig. 6. the change of antibacterial annulus diameter with enzyme dosage and $\mathrm{pH}$ of antibacterial paper made by component enzyme

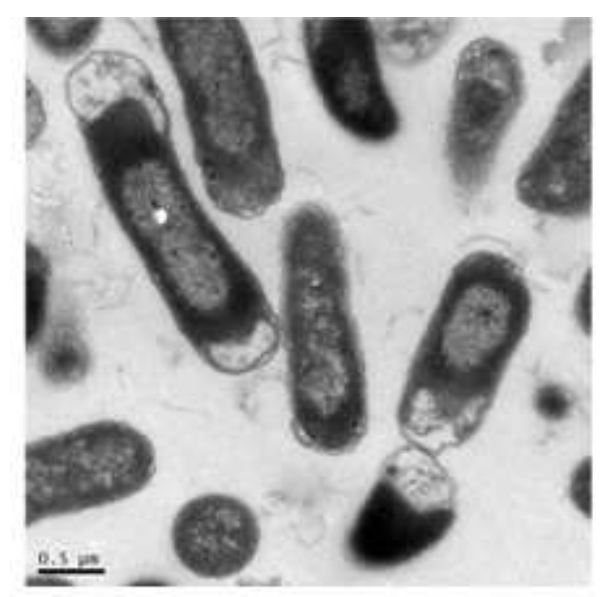

Fig. 7. Photograph of TEM ---E. coli on the edge of antibacterial annulus

\section{Acknowledngements}

Research Plan of Shaanxi Education Department 2014(14JK1109) 'Comparative Genomics Research aboutFast-growig Poplar Fiber Used by Papermaking'. The support is gratefully acknowledged.

\section{References}

[1] Yang Fei, Chen Ke-fu, Yang Ren-dang, You Peng. Anti-Bacteria Agent and Its Application in Antibacterial Paper. China Pulp \& Paper, 2006, 25(8): 51-55.

[2] Yang Kai-ji, Su Wen-qiang, Chen Jing-huan. Development and Application of Multifunctional Antibacterial Paper. China Pulp \&Paper, 2006, 25(8): 51-55.

[3] Lee HJ, Yeo SY, Jeong S H. Antibacterial. effect of nanosized silver colloidal solution on textile fabrics. Journal of Materials Science, 2003, 38(10): 2199

[4] Vliemusedre, Zhou X, Zhang J, Boey F, Zhang H. Direc tElectrochemical Reduction of Single-Layer Graphene Oxide and Subsequent Function alization with Glucose Oxidase. Phys. Chem. C 2009, 113, 14071-14075.

[5] Yu Cheng-hua, Pei Ji-cheng. Chitosan Grafted With Vanillin: Its Antioxidant and Antibacterial Activity and Application in papermaking. China Pulp \& Paper, 2014, 33(5): 1-7.

[6] Agarwal S, Zhou X, Ye F, He Q, Chen, G. Interfacing Live Cells with Nanocarbon Substrates. Langmuir, 2010, 26(112): 2244-2247. 
[7] Liu Bing-yue, Wang Jing, Yao Shu-wei. The use of chitin-copper complex in antibacterium paper, China Pulp \& Paper Industry, 2004, 25(4): 42-45.

[8] He Jin-xing, Chi Guang-jun, He Xiao-ming. A kind of antibacterial poker and its preparation method: China, CN1513572: 2004-07-21.

[9] Klofta, et al. Anhydrous skin lotions having antimicrobial components for application to tissue paper products which mitigate the potential for skin irritation. US, 6238682. 2001-05-29.

[10] Manbde, Zhou X, Ye F, He Q, Chen G. Interfacing Live Cells with Nanocarbon Substrates, Langmuir, 2014, 26(112): 2244-2247.

[11] Coma V, Deschamps A, Gros M. Bioactive packaging materials from edible chitosan polymer antimicrobial activity assessment on dairy related contaminants. Journal of Food Science, 2003, 68(9): 2788.

[12] Young D.H, Knole D.H, Kauss H.E. Effectof chitosan onmembrane permeability of suspension-cultured Glycine max and phaseolus vulgaris cells. Plant Physiology, 1982, 70: 1449. 